\title{
Reactions of alkenes and alkynes with formaldehyde catalyzed by rhodium systems containing phosphine ligands
}

\author{
Merlín Rosales, ${ }^{1 *}$ Beatriz González, ${ }^{1}$ Jessely Molina, ${ }^{1}$ Homero Pérez, ${ }^{1}$ María Modroño-Alonso ${ }^{2}$ \\ and Pablo J. Baricelli ${ }^{2}$ \\ 1 Universidad del Zulia (L.U.Z.), Facultad Experimental de Ciencias. Departamento de Química, Laboratorio de Química \\ Inorgánica (LQI). Maracaibo (Venezuela). \\ 2 Universidad de Carabobo, Facultad de Ingeniería, Centro de Investigaciones Químicas, Valencia (Venezuela). \\ * Corresponding author: Tel +584143602104 FAX +582614127701 \\ Ciudad Universitaria. Módulo 2. Maracaibo. Venezuela \\ e-mail adress: merlin2002@cantv.net; merlinrosalesaiz@gmail.com (M. Rosales)
}

Received October 18 $8^{\text {th }}, 2016$; Accepted March $8^{\text {th }}, 2017$.

\begin{abstract}
The reaction of alkenes (allyl alcohol, styrene and $\mathrm{C}_{6}$ alkenes) with formaldehyde was efficiently performed by using $\mathrm{Rh}$ precatalysts formed in situ by the addition of triphenylphosphine $\left(\mathrm{PPh}_{3}\right), 1,2$-bis(diphenylphosphino)ethane (dppe) or 1,1,1-tris(diphenylphosphinomethyl)ethane (triphos) to the complex $\mathrm{Rh}(\mathrm{acac})(\mathrm{CO})_{2}$ at $130^{\circ} \mathrm{C}$ in 1,4-dioxane, yielding their corresponding aldehydes; the best catalytic system was $\mathrm{Rh}(\mathrm{acac})(\mathrm{CO})_{2} / 2$ dppe, which generates the cationic complex $\left[\mathrm{Rh}\left(\kappa^{2}-\mathrm{P}, \mathrm{P}-\mathrm{dppe}\right)_{2}\right]^{+}$. However, the reaction of phenylacetylene with formaldehyde under the same reaction conditions generated styrene, which was found to be the product of transfer hydrogenation from formaldehyde.

Keywords: hydroformylation; formaldehyde; alkenes; alkynes; rhodium; phosphine.
\end{abstract}

\section{Introduction}

The hydroformylation of unsaturated substrates (alkenes, dienes and alkynes) is a well known synthetic tool for the synthesis of a wide range of organic molecules of high commercial value and it is also one of the largest industrial scale applications of organometallic catalysis for the manufacture of aldehydes and/or alcohols [1-4]. All industrial hydroformylation processes make use of highly toxic and flammable syn-gas (CO and $\mathrm{H}_{2}$ mixture), which has restricted somehow the widely use of hydroformylation in industry and academia. Hence, performing hydroformylation without the use of syn-gas is highly desired and will contribute to the further advancement of sustainable chemistry. Formaldehyde, either in solution (formalin) or as solid (paraformaldehyde), is one of the surrogates for syngas in hydroformylation reactions [5].

However, the version of hydroformylation of alkenes with formaldehyde has received very little attention since the first report of Okano et at. [6] in 1982. In the following three decades, the hydroformylation of unsaturated substrates with formaldehyde has been reported intermittently [7-11] and only recently this area has attracted significant interest, as emphasized by Franke et al. [12] in a review on the hydroformylation
Resumen. La reacción de alquenos (alcohol alílico, estireno y alquenos $\mathrm{C}_{6}$ ) con formaldehido se realizó eficientemente usando precatalizadores de $\mathrm{Rh}$ formados in situ por adición de trifenilfosfina $\left(\mathrm{PPh}_{3}\right)$, 1,2-bis(difenilfosfino)etano (dffe) o 1,1,1-tris(difenilfosfinometil) etano (trifos) al complejo $\mathrm{Rh}(\mathrm{acac})(\mathrm{CO})_{2}$ a $130^{\circ} \mathrm{C}$ en 1,4-dioxano, produciendo los correspondientes aldehídos. El mejor sistema catalítico fue $\mathrm{Rh}(\mathrm{acac})(\mathrm{CO})_{2} / 2 \mathrm{dffe}$, el cual genera el complejo catiónico $\left[\mathrm{Rh}\left(\kappa^{2}-\mathrm{P}, \mathrm{P}-\right.\right.$ $\left.\mathrm{dffe})_{2}\right]^{+}$. Sin embargo, la reacción de fenilacetileno con formaldehido bajo las mismas condiciones de reacción generó estireno, el cual es el producto de la transferencia de hidrógeno del formaldehido.

Palabras clave: hidroformilación; formaldehido; alquenos; alquinos; rodio; fosfina.

reaction and its applications. In fact, some of us reported the potential of rhodium catalysts containing triphenylphosphine $\left(\mathrm{PPh}_{3}\right)$, diphosphines $\left[\mathrm{Ph}_{2} \mathrm{P}\left(\mathrm{CH}_{2}\right)_{\mathrm{n}} \mathrm{PPh}_{2} ; \mathrm{n}=2,3\right.$ and 4$]$ and 1,1,1-tris(diphenylphosphino)ethane (triphos) in the hydroformylation with formaldehyde of 1-hexene (Eq. 1) and other $\mathrm{C}_{6}$ alkenes; the system $\mathrm{Rh}(\mathrm{acac})(\mathrm{CO})_{2} / 2$ dppe [dppe: 1,2-bis(diphenylphosphino)ethane] was the most active precatalyst $[13,14]$. Morimoto et al. [15] reported the highly linear regioselective hydroformylation of 1-alkenes using formaldehyde to give aldehydes by using two rhodium catalysts: $\mathrm{Rh}_{2} \mathrm{Cl}_{2}$ (binap) [binap: 2,2'-bis(diphenylphosphino)-1,1'-binaphthyl] and Rh$\mathrm{H}(\mathrm{CO})_{2}$ (xantphos) [xantphos: 4,5-bis(diphenylphosphino)-9,9-dimethylxanthene]. Taddei et al. [16] showed that this reaction may be accelerated under microwave dielectric heating. Other recent works on the reaction of alkenes, dienes and alkynes with formaldehyde have been also reported [17-23].

There are two possible pathways for the metal-catalyzed hydroformylation of alkenes with formaldehyde (Fig. 1), which proceed through the formation of a hydride-formyl complex, $\mathrm{M}(\mathrm{H})(\mathrm{CHO})$ : i) the classical hydroformylation mechanism (path A), which consists in the decarbonylation of the hydride-formyl intermediate to give either a dihydride-carbonyl intermediate or syn-gas, with the subsequent traditional alkene 


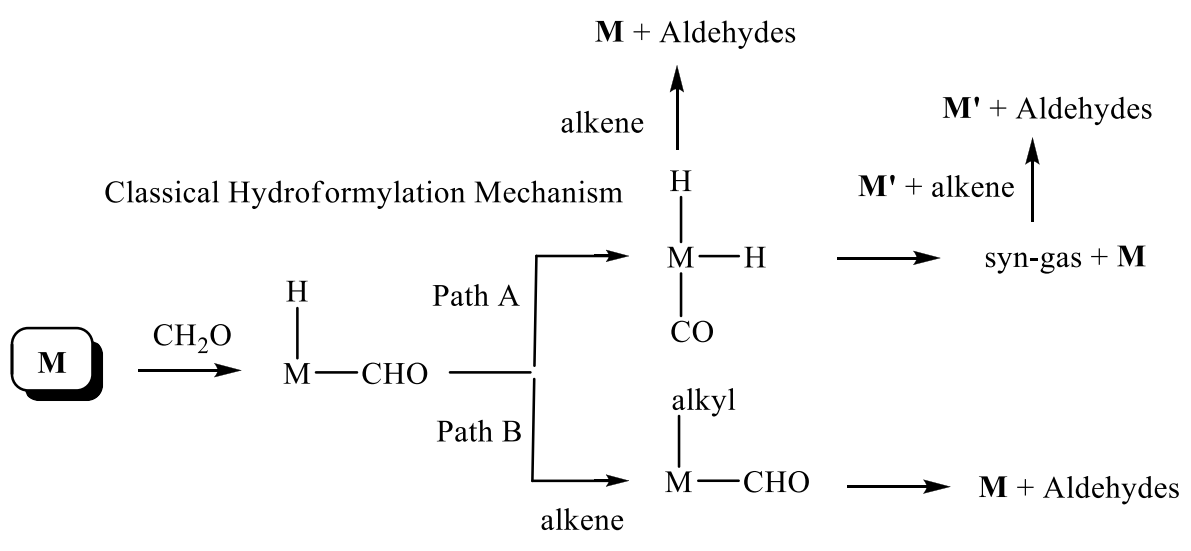

Hydroacylation Mechanism

Fig. 1. Possible pathways for the catalytic hydroformylation of alkenes with formaldehyde.

hydroformylation catalyzed by either the same or other precatalyst, and ii) the hydroacylation mechanism (path B), which occurs by alkene insertion into the $\mathrm{M}-\mathrm{H}$ bond and the reductive elimination of alkyl and formyl ligands.

Morimoto et al. [15] demonstrated that the hydroformylation of 1-alkenes proceeds through the formaldehyde decomposition to give syn-gas catalyzed by a rhodium-binap complex and the posterior classical alkene hydroformylation catalyzed by $\mathrm{Rh}$-xantphos one. More recently, some of us reported a detailed kinetic and mechanistic study of the hydroformylation of 1-hexene with formaldehyde (Eq. 1) catalyzed by [Rh( $\kappa^{2}-\mathrm{P}, \mathrm{P}-$ dppe $)_{2}$ ] acac; experimental results and theoretical DFT calculations proportioned evidences on favor of a hydroacylation mechanism [24].

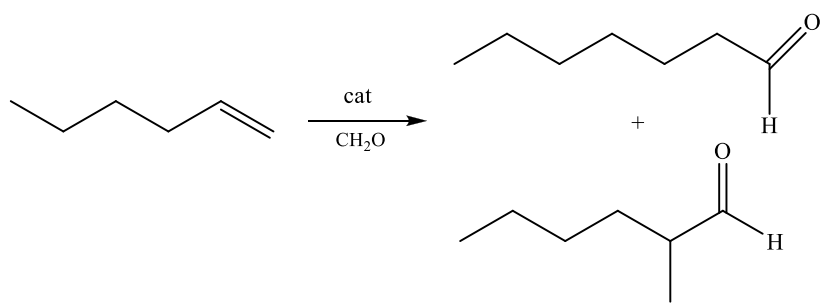

In the present work, we disclose the use of rhodium precatalysts containing $\mathrm{PPh}_{3}$, dppe and triphos for the reaction of other unsaturated substrates (allyl alcohol, styrene and phenylacetylene) with formaldehyde, including some coordination chemistry studies; the initial rates of these reactions were also compared with the hydroformylation of $\mathrm{C}_{6}$ alkenes with formaldehyde.

\section{Results and discussion}

\section{Catalytic reactions of unsaturated substrates with formaldehyde}

The reaction of allyl alcohol, styrene and phenylacetylene with formaldehyde in 1,4-dioxane solution was studied using several rhodium systems, which were formed in situ by the reaction of the complex $\mathrm{Rh}(\mathrm{acac})(\mathrm{CO})_{2}$ with the corresponding equivalents of triphenylphosphine $\left(\mathrm{PPh}_{3}\right)$, 1,2-bis(diphenylphosphino)ethane (dppe) and 1,1,1-tris(diphenylphosphinomethyl)ethane (triphos) at $130{ }^{\circ} \mathrm{C}$.

In Table 1 are summarized the results of the hydroformylation of allyl alcohol (2-propen-1-ol) to produce 4-hydroxy-butanal and 2-methyl-3-hydroxypropanal, products that were identified for the molecular ion peaks at $\mathrm{M}^{+} 88$, besides higher intensity peaks (base peaks) at $\mathrm{m} / \mathrm{z} 42$ and 57 u.m.a corresponding to the loss of 46 units (ethanol) and 31 units (methanol), respectively; propanal was also obtained (17-53\% in $4 \mathrm{~h}$ ), by isomerization of this substrate and subsequent tautomerization, as may be observed in Fig. 2.

Although the unmodified complex $\mathrm{Rh}(\mathrm{acac})(\mathrm{CO})_{2}$ was catalytically inactive for the hydroformylation of allyl alcohol with formaldehyde, the addition of $\mathrm{PPh}_{3}$, dppe and triphos to this complex did induce the formation of the corresponding aldehydes (TON varying from 24 to 195 ) at $130^{\circ} \mathrm{C}$. The highest activity (with the lowest percentage of isomerization-tautomerization to propanal) was obtained when two equivalents of dppe were added to $\mathrm{Rh}(\mathrm{acac})(\mathrm{CO})_{2}$, which generates the cationic

Table 1. Hydroformylation of allyl alcohol with formaldehyde catalyzed by rhodium-phosphine systems

\begin{tabular}{lcccc}
\hline & $\begin{array}{c}\% \\
\text { propanal }\end{array}$ & $\begin{array}{c}\% \\
\text { hydroformylation }\end{array}$ & TON & $1 / \mathrm{b}$ \\
\hline $\mathrm{Rh}(\mathrm{acac})(\mathrm{CO})_{2} / 2 \mathrm{PPh}_{3}$ & 46 & 26 & 78 & 6 \\
$\mathrm{Rh}(\mathrm{acac})(\mathrm{CO})_{2} / 3 \mathrm{PPh}_{3}$ & 48 & 25 & 75 & 7 \\
$\mathrm{Rh}(\mathrm{acac})(\mathrm{CO})_{2} /$ dppe & 53 & 14 & 42 & 23 \\
$\mathrm{Rh}(\mathrm{acac})(\mathrm{CO})_{2} / 2$ dppe & 17 & 65 & 195 & 30 \\
$\mathrm{Rh}(\mathrm{acac})(\mathrm{CO})_{2} /$ triphos & 40 & 8 & 24 & 8 \\
\hline
\end{tabular}

Conditions: $[\mathrm{Rh}]=3.3 \times 10^{-3} \mathrm{M}$, [allyl alcohol $]=1.0 \mathrm{M},\left[\mathrm{CH}_{2} \mathrm{O}\right]=2.5$ $\mathrm{M}, \mathrm{T}=130^{\circ} \mathrm{C}$, solvent $=1,4$-dioxane, $\mathrm{t}=4 \mathrm{~h}, \mathrm{TON}=$ mole of product per mole of catalyst; $\boldsymbol{l} / \boldsymbol{b}=$ linear to branched ratio. 


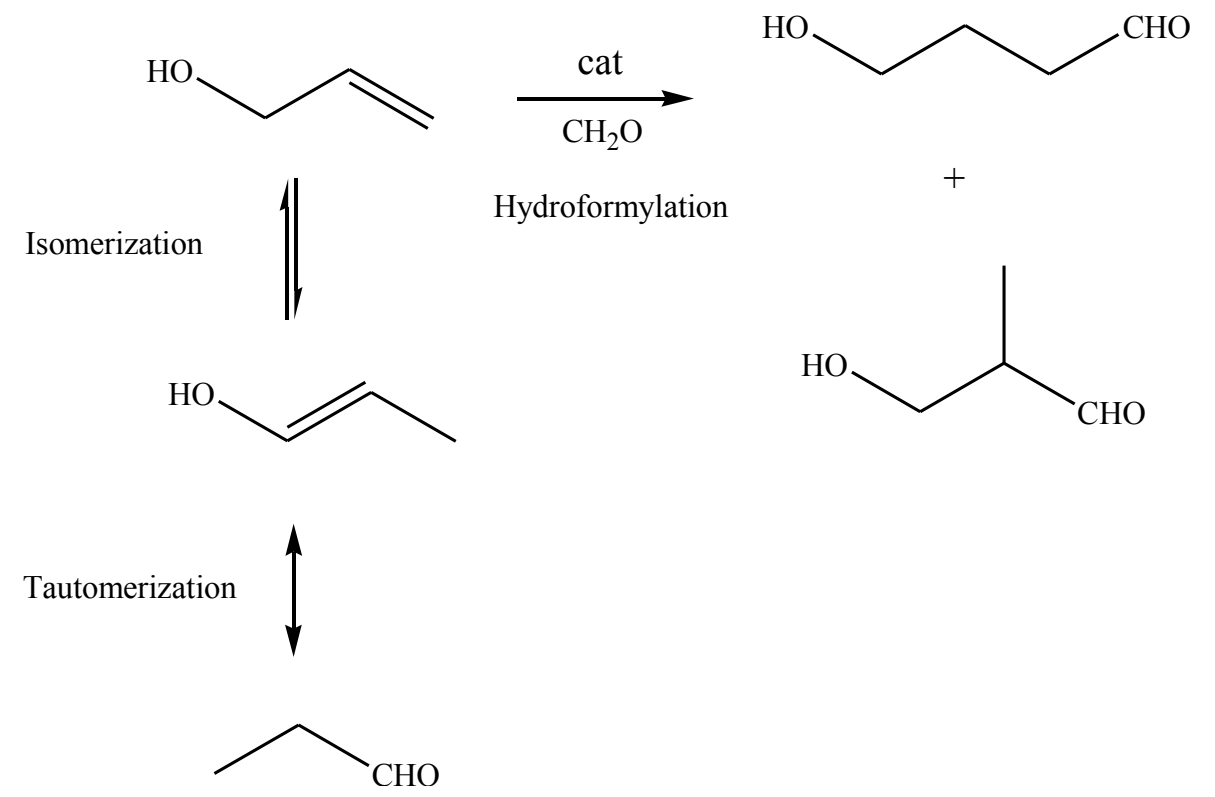

Fig. 2. Products of the catalytic reaction of allyl alcohol with formaldehyde.

complex $\left[\mathrm{Rh}\left(\mathrm{\kappa}^{2} \text {-P,P-dppe }\right)_{2}\right]^{+}$, as reported by Rosales et al. $[13,14,24]$. The catalytic activity of this system was four times higher than the activity generated by addition of 1 eq dppe, twice higher than those generated by addition of 2 or 3 eq. of $\mathrm{PPh}_{3}$ and eight times higher than that of the $\mathrm{Rh}$ /triphos system. Regioselectivities towards the corresponding linear aldehyde were from moderate to high, being the most selective system $\mathrm{Rh} / 2$ dppe $(\boldsymbol{I} / \boldsymbol{b}=30)$. For comparison, under the same reaction conditions, the complex $\mathrm{RhH}(\mathrm{CO})\left(\mathrm{PPh}_{3}\right)_{3}$ displayed a good activity (36 TON in $4 \mathrm{~h}$ ) with high regioselectivity toward the linear aldehyde $(\boldsymbol{l} / \boldsymbol{b}=21)$, results which are concordant with those reported by Seok et al. [11].

On the other hand, these systems were also active for the hydroformylation of styrene with formaldehyde (Eq. 2), under the same reaction conditions (see Table 2), obtaining the corresponding linear and branched aldehydes (3-phenyl- and 2-phenyl-propanal), which were identified by mass spectra (molecular ion peak $\mathrm{M}^{+}$at $\mathrm{m} / \mathrm{z} 134$ ); small amounts of the hydrogenation product (ethylbenzene) were found $(<2 \%)$. The systems $\mathrm{Rh} /$ $\mathrm{nPPh}_{3}$ showed low activities (conversions lower than $10 \%$, TON in the range between 15 and 21, in $4 \mathrm{~h}$ ), and also low regioselectivities toward the linear aldehyde $(\boldsymbol{l} / \boldsymbol{b}=1.6-2.5)$. The system $\mathrm{Rh} / 2$ dppe also showed the highest activity $(\mathrm{TON}=$ $144)$, although the regioselectivity was moderate $(\boldsymbol{l} / \boldsymbol{b}=2.0)$. The production of appreciable amounts of the branched aldehyde (ca. $33 \%$ ) in the reaction catalyzed by $\mathrm{Rh} / 2$ dppe is of special interest for application to the highly enantioselective and regioselective asymmetric hydroformylation of vinylarenes (styrenes and naphthylethylenes) with formaldehyde, which could provide high added-value products such as non-steroidal anti-inflammatory drug intermediates [25].

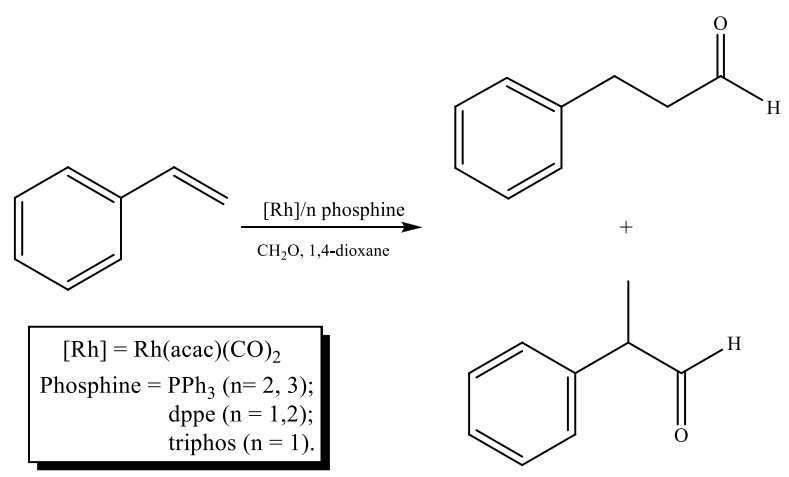

(2)

The results obtained for the hydroformylation of allyl alcohol with formaldehyde catalyzed by rhodium systems containing phosphine ligands differ somewhat to those obtained for the reaction of 1-hexene $[13,14]$ and styrene with formaldehyde by using the same catalytic systems. In fact, for the hydroformylation of simple alkenes (1-hexene and styrene), the order of catalytic activity is $\mathrm{Rh} / 2$ dppe $>\mathrm{Rh} /$ dppe $>\mathrm{Rh} /$ triphos $>\mathrm{Rh} / \mathrm{nPPh}_{3}$, whereas for the hydroformylation of allyl alcohol (an alkene with oxygen atom in $\beta$ position), the order is $\mathrm{Rh} / 2$ dppe $>\mathrm{Rh} /$ $\mathrm{nPPh}_{3}>\mathrm{Rh} / \mathrm{dppe}>\mathrm{Rh} /$ triphos. The higher activity of the Rh/ $\mathrm{nPPh}_{3}$ systems for the hydroformylation of allyl alcohol compared with simple alkenes may be explained by the coordination of the $\mathrm{OH}$ group of the substrate to the metal center, which should hinder the decarbonylation of the formyl group; the coordination of $\mathrm{OH}$ group of the substrate to the metal center has been reported by Seok et al [11] for the hydroformylation of allyl alcohol and acrolein catalyzed by $\mathrm{RhH}(\mathrm{CO})\left(\mathrm{PPh}_{3}\right)_{3}$. Although the hydroformylation of alkenes with formaldehyde 
Table 2. Hydroformylation of styrene with formaldehyde catalyzed by rhodium-phosphine systems.

\begin{tabular}{lccc}
\hline Catalytic System & $\begin{array}{c}\% \\
\text { conversion }\end{array}$ & TON & $1 / \mathrm{b}$ \\
\hline $\mathrm{Rh}(\mathrm{acac})(\mathrm{CO})_{2} / 2 \mathrm{PPh}_{3}$ & 7 & 21 & 1.6 \\
$\mathrm{Rh}(\mathrm{acac})(\mathrm{CO})_{2} / 3 \mathrm{PPh}_{3}$ & 5 & 15 & 2.5 \\
$\mathrm{Rh}(\mathrm{acac})(\mathrm{CO})_{2} / \mathrm{dppe}$ & 35 & 105 & 1.4 \\
$\mathrm{Rh}(\mathrm{acac})(\mathrm{CO})_{2} / 2$ dppe & 48 & 144 & 2.0 \\
$\mathrm{Rh}(\mathrm{acac})(\mathrm{CO})_{2} /$ triphos & 21 & 63 & 1.9 \\
\hline
\end{tabular}

Conditions: $[\mathrm{Rh}]=3.3 \times 10^{-3} \mathrm{M}$, [styrene $]=1.0 \mathrm{M},\left[\mathrm{CH}_{2} \mathrm{O}\right]=2.5 \mathrm{M}$, $\mathrm{T}=130^{\circ} \mathrm{C}$, solvent $=1,4$-dioxane, $\mathrm{t}=4 \mathrm{~h}, \mathrm{TON}=$ mole of product per mole of catalyst; $\boldsymbol{l} / \boldsymbol{b}=$ linear to branched ratio.

catalyzed by $\mathrm{Rh} / 2$ dppe proceeds via hydroacylation mechanism [24], the reaction catalyzed by $\mathrm{Rh} / \mathrm{nPPh}_{3}$ and $\mathrm{Rh} / 1 \mathrm{dppe}$ systems probably proceeds through a classic mechanisms in view of experimental evidences obtained in the coordination chemistry reported in the present work (vide infra). In fact, the $\mathrm{Rh} / 3 \mathrm{PPh}_{3}$ system is a more active precatalyst than $\mathrm{Rh} /$ dppe one for the alkene hydroformylation under syngas conditions.

For comparative effects, Table 3 shows the measured reaction rates for the hydroformylation with formaldehyde of some olefins catalyzed by $\left[\mathrm{Rh}(\mathrm{dppe})_{2}\right]$ acac, the most active precatalyst. 3,3-Dimethylbut-1-ene and 2,3-dimethylbut-1-ene were hydroformylated exclusively to their corresponding linear products (4,4- and 3,4-dimethylpentanal, respectively), presumably due to steric impediments for the formation of the branched alkyl intermediates. As may be observed, the simple alkenes without steric effect (3,3-dimethyl-1-butene and 1-hexene) were hydroformylated faster than 2,3-dimehyl-1-butene at $100^{\circ} \mathrm{C}$, whereas styrene (vinyl arene), allyl alcohol (alkene with an oxygen in $\beta$ position) and cyclohexene (cyclic alkene) require a higher temperature $\left(130^{\circ} \mathrm{C}\right)$. Finally, the internal alkene, 2,3-dimehyl-2-butene, was not hydroformylated under these reaction conditions due to steric hindrance. The order of reactivity of these alkenes is:

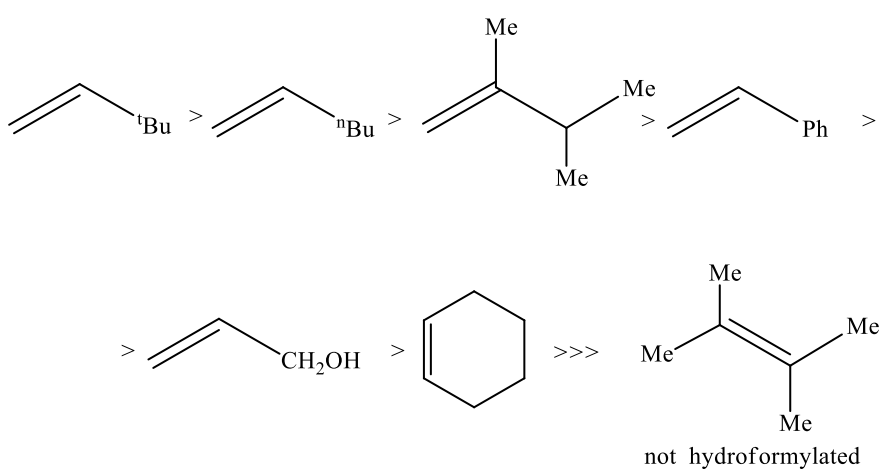

On the other hand, the $\boldsymbol{l} / \boldsymbol{b}$ ratio was moderate for 1 -hexene and styrene $(\boldsymbol{l} / \boldsymbol{b}=1.7$ and 2.0 , respectively) whereas a highly linear regioselective hydroformylation was observed for allyl alcohol susbtrate $(\boldsymbol{l} / \boldsymbol{b}=30)$. These results are interesting because the system $\mathrm{Rh} / 2$ dppe catalyzes the hydroformylation with formaldehyde of either simple alkenes (aliphatic and cyclic alkenes and vinylarenes) or alkenes containing oxygen at the $\beta$ position to the carbon-carbon double bond, contrary to the results obtained by Seok et al. [11], who found that the complex $\mathrm{RhH}(\mathrm{CO})\left(\mathrm{PPh}_{3}\right)_{3}$ was more active for the hydroformylation with formaldehyde of alkenes containing oxygen at the $\beta$ position to the carbon-carbon double bond than for simple alkenes, for which lower activities were found.

Finally, the reaction of phenylacetylene with formaldehyde catalyzed by $\mathrm{Rh} /$ phosphine systems, under the same reaction conditions $\left(130^{\circ} \mathrm{C}, 4 \mathrm{~h}\right)$, did not generate the corresponding unsaturated aldehydes (3-phenyl- and 2-phenyl-propenal). Instead, styrene was almost quantitatively obtained in these reactions in $4 \mathrm{~h}$, which may be the product of hydrogen transfer product of the formaldehyde or from the 1,4-dioxane solvent [26]. To demonstrate this, the same reactions were carried out in absence of formaldehyde; under these conditions phenylacetylene

Table 3. Comparison of reaction rates for the olefin hydroformylation with formaldehyde catalyzed by $\left[\mathrm{Rh}(\mathrm{dppe})_{2}\right]$ acac.

\begin{tabular}{|c|c|c|c|c|}
\hline Olefin & $\begin{array}{l}\text { Hydroformylation } \\
\text { Products }\end{array}$ & $10^{5} \boldsymbol{r}_{\boldsymbol{i}}\left(\mathrm{Ms}^{-1}\right)$ & $\begin{array}{l}\% \text { Conversion } \\
(5 \mathrm{~h})\end{array}$ & $1 / \mathrm{b}$ \\
\hline 1-hexene ${ }^{a}$ & $\begin{array}{l}\text { Heptanal } \\
\text { 2-methylhexanal }\end{array}$ & $8.09 \pm 0.11$ & 41 & 1.7 \\
\hline 3,3-dimethyl-1-butene ${ }^{a}$ & 4,4-dimethylpentanal & $14.8 \pm 0.21$ & 48 & - \\
\hline 2,3-dimehyl-1-butene ${ }^{a}$ & 3,4-dimethylpentanal & $0.18 \pm 0.02$ & 4 & - \\
\hline Styrene $^{\mathrm{b}}$ & $\begin{array}{l}\text { 3-phenylpropanal } \\
\text { 2-phenylpropanal }\end{array}$ & $3.31 \pm 0.05$ & 23 & 2.0 \\
\hline Allyl alcohol ${ }^{\mathrm{b}}$ & $\begin{array}{l}\text { 4-hidroxybutanal } \\
\text { 3-hidroxypropanal }\end{array}$ & $1,66 \pm 0.03$ & 13 & 30.1 \\
\hline Cyclohexene $^{\mathrm{b}}$ & Cyclohexylcarboxaldehyde & $0.15 \pm 0.03$ & 5 & - \\
\hline 2,3-dimehyl-2-butene ${ }^{b}$ & & - & 0 & - \\
\hline
\end{tabular}

Conditions: $[\mathrm{Rh}]=1.7 \times 10^{-3} \mathrm{M}$, [olefin] $=0.13 \mathrm{M},\left[\mathrm{CH}_{2} \mathrm{O}\right]=0.5 \mathrm{M}, \mathrm{T}=100^{\circ} \mathrm{C}^{\mathrm{a}}, 130^{\circ} \mathrm{C}^{\mathrm{b}} ; \boldsymbol{l} / \boldsymbol{b}=$ linear to branched ratio. 
was not hydrogenated, which indicates that the hydrogenation of this substrate proceeds through decomposition of formaldehyde [27] and hydrogen transfer toward the metal center yielding rhodium-dihydride species and subsequently from rhodium to phenylacetylene.

\section{Reactions of the Rh/dppe systems with formaldehyde}

In order to gain further understanding on the mechanism of hydroformylation of unsaturated substrates with formaldehyde, the interaction of $\mathrm{Rh}(\mathrm{acac})(\mathrm{CO})_{2}$ with dppe and formaldehyde was studied; the results are shown in Fig. 3. In previous works, we have reported that reaction of the dicarbonylrhodium complex with 2 equivalents of dppe in 1,4-dioxane solution under reflux produces the cationic complex $\left[\mathrm{Rh}\left(\kappa^{2}-\mathrm{P}, \mathrm{P}-\mathrm{dppe}\right)_{2}\right]^{+}(\mathbf{1})$, as its acetylacetonate (acac) salt $[13,14]$; coordination chemistry and theoretical DFT studies followed us to propose that complex $\mathbf{1}$ is the active catalytic species. When the reaction of this complex with an excess of formaldehyde $\left(\left[\mathrm{CH}_{2} \mathrm{O}\right] /[\mathrm{Rh}]=\right.$ 10) was carried out, it was impossible to detect any other species different than the cationic bis(dppe)rhodium complex [24]. We considered that the cationic bis(dppe)rhodium complex reacted reversibly with formaldehyde to produce $[\mathrm{RhH}(\mathrm{CHO})$ $\left.\left(\kappa^{2} \text {-P,P-dppe }\right)_{2}\right]^{+}(2)$, which in absence of an unsaturated substrate (alkene or alkyne) come back to $\mathbf{1}$. Now, we performed these reactions by using only one equivalent of dppe. When the reaction of $\mathrm{Rh}(\mathrm{acac})(\mathrm{CO})_{2}$ with 1 equivalent of dppe was carried out, the presence of complex $\left[\mathrm{Rh}\left(\mathrm{\kappa}^{2}-\mathrm{P}, \mathrm{P}-\mathrm{dppe}\right)_{2}\right]^{+}$(approximately $50 \%$ ) was observed as the only phosphorous complex; in some reactions, a small amount of a carbonyl complex was detected by IR ( $v$ CO in $1960 \mathrm{~cm}^{-1}$ ), which is probably $\mathrm{Rh}(\mathrm{acac})$ $(\mathrm{CO})\left(\kappa^{1}-\mathrm{P}\right.$-dppe) (3) by comparison with the triphenylphosphine analogue complex, namely $\mathrm{Rh}(\mathrm{acac})(\mathrm{CO})\left(\mathrm{PPh}_{3}\right)$ [28]. The same reaction in the presence of an excess of formaldehyde mainly produces a mixture of two carbonyl complexes, as detected by IR $\left(v C O=2100,2055\right.$ and $\left.2010 \mathrm{~cm}^{-1}\right)$ and ${ }^{31} \mathrm{P}\left\{{ }^{1} \mathrm{H}\right\}$

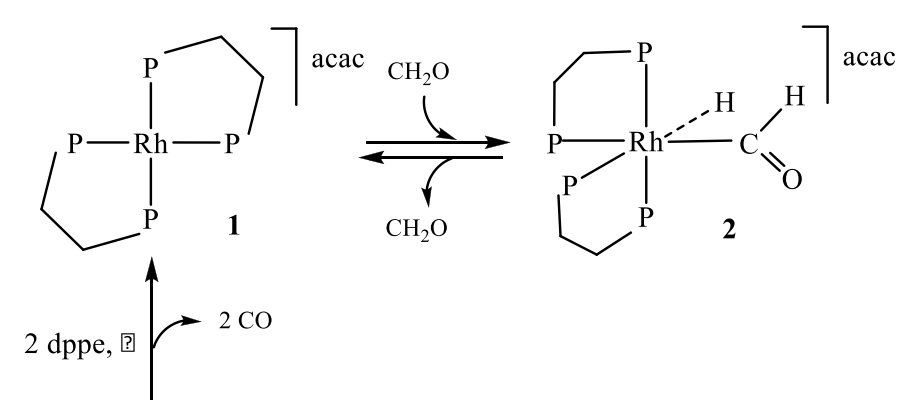

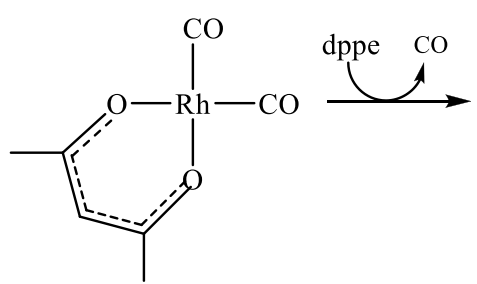<smiles>CCCP[R]1(C(=O)[O-])C=C(C)C=C(C)O1</smiles>

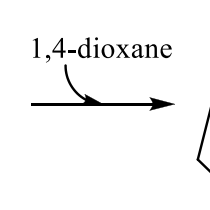

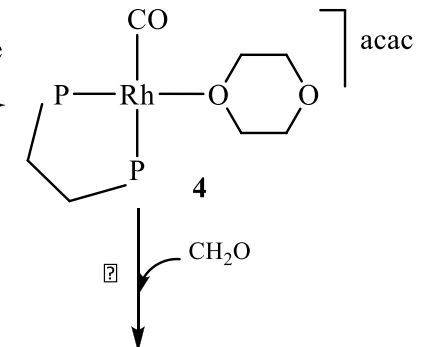<smiles>[H][R]([H])(C(=O)C(C)C)[PH](C)C</smiles>

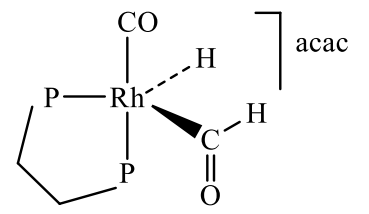<smiles>[Y]C(C)C</smiles>

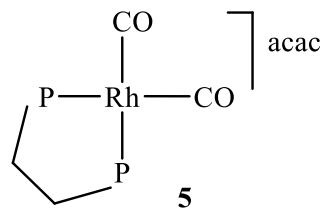

Fig. 3. Reactions of $\mathrm{Rh}(\mathrm{acac})(\mathrm{CO})_{2}$ with dppe and formaldehyde. 
NMR, a monocarbonyl complex, possibly $[\mathrm{Rh}(\mathrm{CO})(1,4-$ dioxane $\left.)\left(\kappa^{2}-\mathrm{P}, \mathrm{P}-\mathrm{dppe}\right)\right]^{+}(\mathbf{4})$, and small amounts of the dicarbonyl one, namely $\left[\mathrm{Rh}(\mathrm{CO})_{2}\left(\kappa^{2}-\mathrm{P}, \mathrm{P}-\mathrm{dppe}\right)\right]^{+}(\mathbf{5})$. The monocarbonyl complex $\left(v C O=2010 \mathrm{~cm}^{-1}\right)$ showed in the ${ }^{31} \mathrm{P}\left\{{ }^{1} \mathrm{H}\right\}$ NMR spectrum two doublets of doublets (dd) centered at 67.0 and $66.9 \mathrm{ppm}$ with coupling constants ${ }^{1} J_{\mathrm{Rh}-\mathrm{P}}=131 \mathrm{~Hz}$ and ${ }^{2} J_{\mathrm{P}-\mathrm{P}}=12$ $\mathrm{Hz}$, whereas the dicarbonyl complex $(\mathrm{vCO}=2100$ and 2055 $\mathrm{cm}^{-1}$ ) showed a doublet at $67.0 \mathrm{ppm}\left[{ }^{1} J_{\mathrm{Rh}-\mathrm{P}}=155 \mathrm{~Hz}\right]$. Complex 4 may be formed from 3 by dissociation of an acac ligand and the subsequent coordination of both the other arm of dppe ligand as well as of a molecule of 1,4-dioxane, whereas complex 5 may be obtained by the reaction of $\mathbf{4}$ with formaldehyde to produce initially a hydride-formyl intermediate, $[\mathrm{RhH}(\mathrm{CHO})$ $\left.(\mathrm{CO})\left(\kappa^{2}-\mathrm{P}, \mathrm{P}-\mathrm{dppe}\right)\right]^{+}$, which suffers decarbonylation to generate a dihydride-dicarbonyl complex and finally the reductive elimination of dihydrogen. Fairlie and Bosnich [29] reported the synthesis of the $\mathrm{ClO}_{4}$ salt of complex $\mathbf{5}$, as well as similar complexes related to 4 , namely $\left[\mathrm{Rh}(\mathrm{CO})(\right.$ ketone $\left.)\left(\kappa^{2}-\mathrm{P}, \mathrm{P}-\mathrm{dppe}\right)\right]$ $\mathrm{ClO}_{4}$ (ketone: acetone and cyclopentanone).

These results indicate that in presence of one equivalent of dppe, the rhodium- catalyzed hydroformylation with formaldehyde probably proceed through a classical mechanism via formaldehyde decomposition. Perhaps, the hydroformylation of alkenes with formaldehyde employing the $\mathrm{Rh} / \mathrm{nPPh}_{3}$ catalytic systems occurs through of a similar route than the $\mathrm{Rh} /$ dppe-catalyzed reaction.

\section{Mechanistic proposal for the reactions of unsaturated substrates with formaldehyde}

On the basis of experimental findings and the present knowledge of these reactions $[15,24]$, we propose a plausible general mechanism for the reaction of the different substrates (alkenes and alkynes) with formaldehyde catalyzed by rhodium-phosphine systems, which is shown in Fig. 4. The catalytic cycle

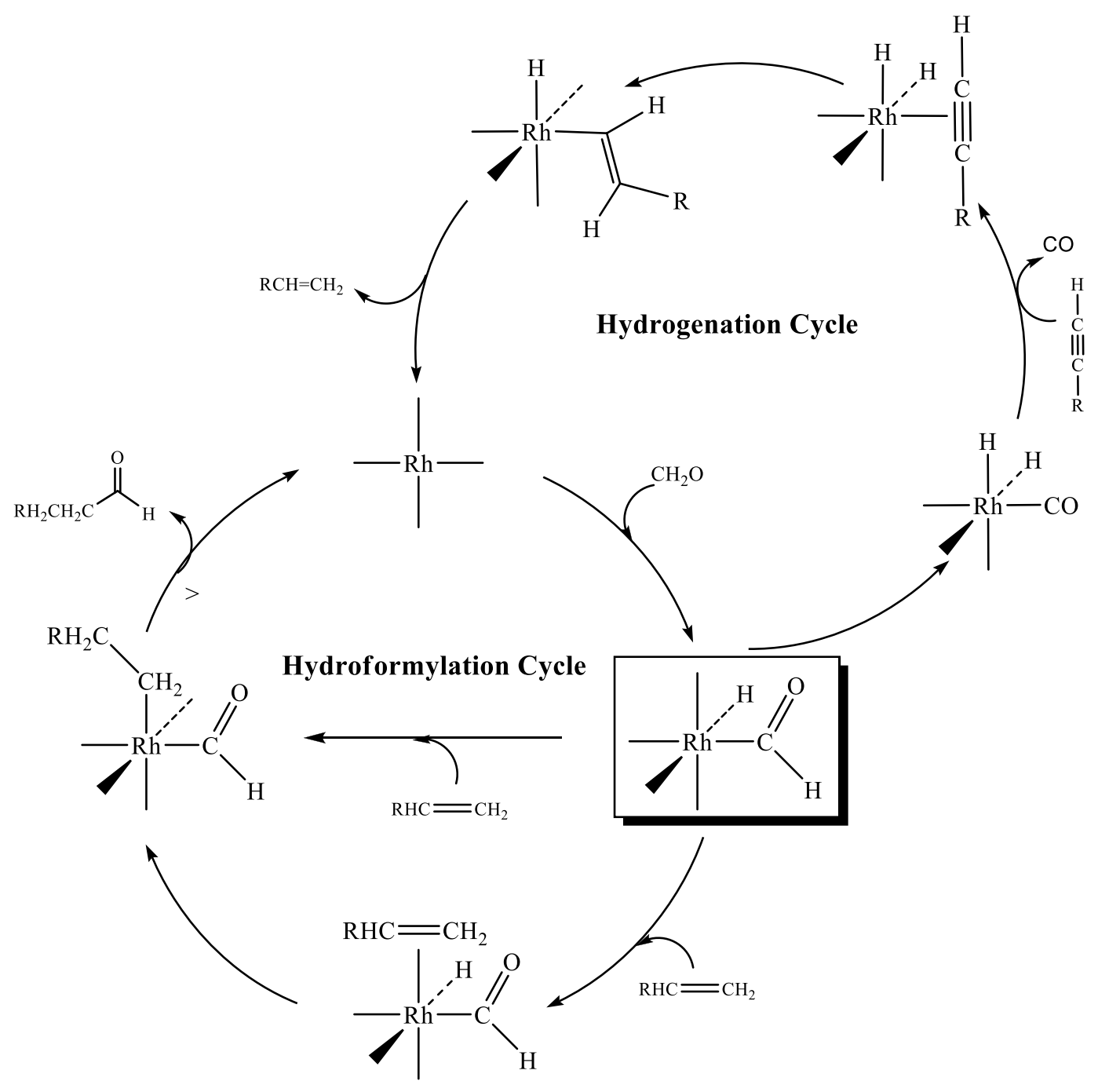

Fig. 4. Proposed catalytic cycle for the reaction of alkenes and alkynes with formaldehyde catalyzed by rhodium-phosphine systems. 
is initiated with the oxidative addition of formaldehyde $\mathrm{C}-\mathrm{H}$ bond to generate a hydride-formyl rhodium species, which we suppose is the key intermediate of both cycles. For hydroformylation of alkenes with $\mathrm{Rh} / 2$ dppe system, the following steps are the insertion of olefin into the $\mathrm{Rh}-\mathrm{H}$ bond to generate an alkyl-formyl species and, finally, the reductive elimination of the corresponding aldehydes to regenerate the active species and restart the cycle; when $\mathrm{Rh} / \mathrm{dppe}$ or $\mathrm{Rh} / \mathrm{nPPh}_{3}$ systems are used as precatalysts, the reaction occurs probably through a classical hydroformylation mechanism (see Fig. 1). On the other hand, if the substrate is phenylacetylene, the hydride-formyl species suffers the decarbonylation of the formyl group to yield a dihydro-carbonyl species; substitution of $\mathrm{CO}$ ligand by phenylacetylene followed by the subsequent hydride transfer toward one of the carbon atom containing the triple bond and the reductive elimination of styrene completes the catalytic hydrogenation cycle.

\section{Conclusions}

The hydroformylation of the carbon-carbon double bond of allyl alcohol and styrene was performed with formaldehyde by using rhodium-phosphine precatalysts in dioxane at $130{ }^{\circ} \mathrm{C}$. The best system was that formed in situ by addition of 2 eq of dppe to the complex $\mathrm{Rh}(\mathrm{acac})(\mathrm{CO})_{2}$, yielding the cationic species $\left[\mathrm{Rh}\left(\mathrm{\kappa}^{2}-\mathrm{P}, \mathrm{P}-\mathrm{dppe}\right)_{2}\right]^{+}$, which displayed the highest activity. However, the reaction of phenylacetylene with formaldehyde under the same reaction conditions did generate styrene, which is the product of hydrogen transfer from the formaldehyde.

\section{Experimental Section}

\section{Chemicals}

Substrates (1-hexene, allyl alcohol, styrene, 3,3-dimethyl-1-butene, 2,3-dimethyl-1-butene, 2,3-dimethyl-2-butene and phenylacetylene) and the catalytic reaction solvent [1,4-dioxane (Riedel de Haens)] were purified by known procedures and distillated at reduced pressure before using [30]. $\mathrm{CDCl}_{3}$ (Aldrich) was dried using activated molecular sieves. Other chemicals $\left[\mathrm{RhCl}_{3} \cdot \mathrm{xH}_{2} \mathrm{O}, \mathrm{PPh}_{3}\right.$, dppe and triphos (Stream Chemicals) and paraformaldehyde (Aldrich)] and solvents [toluene (Riedel de Haens), cycloheptane, ethylacetate and n-pentane (Merck)] were used as received.

\section{General procedure}

All manipulations were conducted with the rigorous exclusion of air using a vacuum line, an argon-filled Schlenk line and/or an argon-filled glovebox. Complex $\mathrm{Rh}(\mathrm{acac})(\mathrm{CO})_{2}$ was prepared from $\mathrm{RhCl}_{3} \cdot \mathrm{xH}_{2} \mathrm{O}$ by a published procedure [28] whereas formaldehyde was generated in situ in the reaction medium dissolving paraformaldehyde in 1,4-dioxane.

\section{Physical measurements}

The products of the catalytic reactions were analyzed by GC using a 3300 Series VARIAN instrument fitted with a flame ionization detector (FID) and a $2 \mathrm{~m} 20 \%$ SP-2100 on a 0.1 $\%$ carbowax 100/120 Supelcoport column, using $\mathrm{N}_{2}$ as carrier gas; the results were quantified with a VARIAN 4400 microcomputer. The products were additionally analyzed by a $\mathrm{GC} /$ MS HP 5890/5971 coupled system using a Quadrex PONA 5\% phenyl methyl silicone, $25 \mathrm{~m}, 320 \mu \mathrm{m}$ column. Cycloheptane, ethyl acetate and toluene were used as internal standards for the reactions of $\mathrm{C}_{6}$ alkenes, allyl alcohol and styrene and phenylacetylene, respectively. The IR spectra (in $\mathrm{KBr}$ disk) were recorded on a Shimadzu 8300 FT-IR instrument. ${ }^{31} \mathrm{P}\left\{{ }^{1} \mathrm{H}\right\}$ NMR spectra were recorded on a Bruker AM-300 spectrometer; chemical shift are expressed in p.p.m. upfield from $\mathrm{H}_{3} \mathrm{PO}_{4}$.

\section{Catalytic reactions}

The catalytic reactions were performed in a Fischer Porter reactor, in which a solution of $\mathrm{Rh}(\mathrm{acac})(\mathrm{CO})_{2}(0.05 \mathrm{mmol})$, the required amount of the corresponding phosphine, the substrate (15 mmol), formaldehyde $(1.125 \mathrm{~g}, 40 \mathrm{mmol})$, the corresponding internal standard $(8.3 \mathrm{mmol})$ and 1,4-dioxane (total volume $15 \mathrm{~mL}$ ) were placed in the reactor. The system was flushed three times with argon and then heated to the desired reaction temperature; after $4 \mathrm{~h}$ with constant stirring, the system was cooled in ice. At the end of the catalytic reactions, the products were analyzed by GC.

\section{Measurements of the initial rate of reactions}

In order to measure the initial rate of the hydroformylation of olefins with formaldehyde, all the runs were performed at low conversions [31], by using a Parr Instrument high-pressure reactor. This reactor was provided with an arrangement for sampling of liquid contents, besides of automatic temperature, pressure and variable stirrer speed controls. In a typical experiment, a solution of the catalytic system, the corresponding substrate, formaldehyde, the internal standard $(8.3 \mathrm{mmol})$ and 1,4-dioxane (total volume $30 \mathrm{~mL}$ ) was placed in the reactor. The solution was deoxygenated and charged with argon at atmospheric pressure and the reactor was heated to the desired temperature. Aliquots of the reaction mixture were taken at regular intervals of time, which were monitored by using GC.

The data of the reactions were plotted as molar concentration of the products versus time in seconds yielding straight lines, which were fitted by conventional linear regression programs $\left(\mathrm{r}^{2}>0.95\right)$; initial rates of the reaction $\left(\boldsymbol{r}_{i}\right)$ were obtained from the corresponding slopes.

\section{Reactions of $\mathrm{Rh}(\mathrm{acac})(\mathrm{CO})_{2}$ with dppe and formaldehyde}

These reactions were performed by the interaction of $\mathrm{Rh}(\mathrm{acac})$ $(\mathrm{CO})_{2}(103 \mathrm{mg}, 0.4 \mathrm{mmol})$ with one $(160 \mathrm{mg}, 0.4 \mathrm{mmol})$ or two equivalents $(320 \mathrm{mg}, 0.8 \mathrm{mmol})$ of dppe in the presence or 
absence of a ten-fold excess of formaldehyde (120 mg, $4 \mathrm{mmol})$ in 1,4-dioxane $(10 \mathrm{~mL})$ under reflux for $2 \mathrm{~h}$. The corresponding solution was evaporated until dryness and the solid was washed with n-pentane.

\section{Acknowledments}

We thank to División de Investigación of the Facultad Experimental de Ciencias and Consejo de Desarrollo Científico y Humanístico (CONDES) of the Universidad del Zulia (L.U.Z.) for finantial supports.

\section{References}

1. Van Leeuwen, P. C. J.; Claver, C., Eds., Rhodium catalyzed hydroformylation, Kluwer Academic Publishers, 2000.

2. Frohning, C.D.; Kohlpaintner, C.W.; Bohnen, H.-W., in: Applied Homogeneous Catalysis with Organometallic Compounds, Vol. 1, Cornils, B.; Herrmann, W.A., Eds., Wiley-VCH, Weinheim, 2002, 31-103.

3. Bhaduri, S.; Mukesh, D. Homogeneous Catalysis: Mechanisms and Industrial Applications. Wiley-Interscience, Ed. New York, 2014, 141-152.

4. Whiteker, G.T.; Cobley, C.J. Top Organometal. Chem. 2012, 42, 35-46.

5. Wu, L.; Liu, Q.; Jackstell, R.; Beller, M. Angew. Chem. Int. Ed. 2014, 53, 6310-6320.

6. Okano, T.; Kobayashi, T.; Konishi, H.; Kiji, J. Tetrahedron Lett. 1982, 23, 4967-4968.

7. Jenner, G.; Nahmed, E. M.; Libs-Konrath, S. J. Mol. Catal. 1991, 64, 337-347.

8. Aika, K.; Sekija, H.; Ozaki, A. C1 Mol. Chem. 1984, 1, 65-67.

9. Blackborow, J. R.; Daroda, R. J.; Wilkinson, G. Coord. Chem. Rev. 1982, 43, 17-38.

10. Lassaletta, J. M.; Fernández, R.; Gasch, C.; Vasquez, J. Tetrahedron 1996, 52, 9143-9160.

11. Ahn, H. S., Han, S. H.; Uhm, S. J.; Seok, W. K., Lee, H. N.; Korneeva, G. A. J. Mol. Catal. A: Chemical 1999, 144, 295-306.
12. Franke, B.; Selent, D.; Börner, A. Chem. Rev. 2012, 112, 5675-5732.

13. Rosales, M.; González, A.; González, B.; Moratinos, C.; Pérez, H.; Urdaneta, J.; Sánchez-Delgado, R. J. Organomet. Chem. 2005, 690, 3095-3098.

14. Rosales, M.; Arrieta, F.; González, A.; Baricelli, P. J., González, B.; Guerrero, Y.; Moratinos, C.; Pacheco, I.; Pérez, H.; Urdaneta, J. Catal. Lett. 2008, 126, 367-370.

15. Makado, G.; Morimoto, T.; Sugimoto, Y.; Tsutsumi, K.; Kagawa, N.; Kakiuchi, K. Adv. Synth. Catat. 2010, 352, 299-304.

16. Cini, E.; Airiau, E.; Girard, N.; Mann, A.; Salvadori, J.; Taddei, M. Synlett. 2011, 199-202.

17. Fuji, K.; Morimoto, T.; Tsusumi, K.; Kakiuchi, K. Angew. Chem. Int. Ed. 2003, 42, 2409-2411.

18. Fuji, K.; Morimoto, T.; Tsutsumi, K.; Kakiuchi, K. Tetrahedron Lett. 2004, 45, 9163-9166.

19. Fuji, K.; Morimoto, T.; Tsutsumi, K.; Kakiuchi, K. Chem. Commun. 2005, 3295-3297.

20. Morimoto, T.; Fujioka, M.; Fuji, K.; Tsutsumi, K.; Kakiuchi, K. J. Organomet. Chem. 2007, 692, 625-634.

21. Morimoto, T.; Yamasaki, K.; Hirano, A.; Tsutsumi, K.; Kagawa, N.; Kakiuchi, K.; Harada, Y.; Fukimoto, Y.; Chatani, N.; Nishioka, T. Org. Lett. 2009, 11, 1777-1780.

22. Uhlemann, M.; Doerfelt, S.; Börner, A. Tetrahedron Lett. 2013, 54, 2209.

23. Köpfer, A.; Sam, B.; Breit, B.; Krische, M. J. Chem. Sci. 2013, 4, 1876-1880.

24. Rosales, M.; Pérez, H.; Arrieta, F.; Izquierdo, R.; Moratinos, C.; Baricelli, P. J. J. Mol. Catal. A: Chemical 2016, 421, 122-130.

25. Nozaki, K., in: Comprehensive Assymetric Catalysis, Jacobsen, E. N.; Pfaltz, A.; Yamamoto, H., Eds., Springer-Verlag, Berlin, 1999.

26. Brtieger, G.; Nestrick, T. J. Chem. Rev. 1974, 74, 567-580.

27. Beck, C. M.; Rathmill, S. E.; Park, Y. J.; Chen, J.; Crabtree, R. H. Organometallics 1999, 18, 5311.

28. Varshavskii, Y. S.; Cherkasova, T. G. Russ. J. Inorg. Chem. (Engl. Transl) 1967, 12, 899.

29. Fairlie, D. P.; Bosnich, B. Organometallics 1988, 7, 946-954.

30. Perrin, D.; Armarego, W.L.F., Purification of Laboratory Chemicals, 3rd. Ed., Pergamon Press, Great Britain, 1988.

31. Casado, J.; López-Quintela, M.A.; Lorenzo-Barral, F.M., J. Chem. Educ. 1986 63, 450-455. 